\title{
INTERACTION OF HYDROGEN WITH OXYGEN ON Cu(111)
}

\author{
C.M.A.M. MESTERS, T.J. VINK, O.L.J. GIJZEMAN and J.W. GEUS \\ Van 't Hoff Laboratory for Physical and Colloid Chemistry, University of Utrecht, Padualaan 8, 3584 \\ $\mathrm{CH}$ Utrecht, The Netherlands
}

Received 24 February 1983; accepted for publication 26 August 1983

The kinetics of the interaction of hydrogen with oxygen adsorbed on $\mathrm{Cu}(111)$ up to 0.5 monolayer is studied with ellipsometry. It is shown that hydrogen dissociates at $\mathrm{Cu}$ sites and that an important step is the formation of $\mathrm{OH}_{(\text {ad) }}$ from $\mathrm{O}_{(\mathrm{ad})}$ and $\mathrm{H}_{(\mathrm{ad})}$ with an activation energy of $93 \pm 12 \mathrm{~kJ} / \mathrm{mol}$. The operation of an ionization gauge changes the reaction mechanism in the sense that it facilitates hydrogen dissociation. In this case the overall activation energy is only $5 \mathrm{~kJ} / \mathrm{mol}$.

\section{Introduction}

The adsorption of oxygen on $\mathrm{Cu}$ single crystals [1-8] and the dissociative hydrogen chemisorption [9-11] have been studied extensively. Few investigations, however, are concerned with the reaction between hydrogen and oxygen on copper single crystal surfaces [12].

The interaction of carbon monoxide with oxygen adsorbed on copper surfaces has been studied [1-4] and from a catalytic point of view it is interesting to investigate whether there is a pronounced difference in the reactivity of preadsorbed oxygen towards carbon monoxide and hydrogen.

The present paper is concerned with the reaction between hydrogen and adsorbed oxygen (up to 0.5 monolayer) on a $\mathrm{Cu}(111)$ surface.

\section{Experimental}

The experiments were performed in a standard UHV system equipped with facilities for AES, LEED and ellipsometry. The surface was cleaned by cycles of sputtering (typically $500 \mathrm{eV} \mathrm{Ar}{ }^{+}, 5 \mu \mathrm{A} / \mathrm{cm}^{2}$, angle of incidence $45^{\circ}, 35$ $\mathrm{min}$ ) and annealing $\left(15 \mathrm{~min}, 450^{\circ} \mathrm{C}\right)$. Auger spectra showed less than $3 \%$ of a monolayer oxygen contamination on the $\mathrm{Cu}(111)$ surface. Ellipsometric measurements were carried out with an automatic nulling ellipsometer which continuously measured minima in polarizer and analyser settings as a function of time in one zone. Off null irradiance measurements were carried out for comparison with previous results [1]. 
The clean $\mathrm{Cu}(111)$ surface was covered with half a monolayer of oxygen, by exposing the surface to $780 \mathrm{~L} \mathrm{O}_{2}$ at a crystal temperature of $195^{\circ} \mathrm{C}$. The saturation value of $\delta \Delta$ was $0.7 \pm 0.07^{\circ}$ which is in very close agreement with the results of Habraken et al. [1]. According to these results it can be concluded that the relation between the ellipsometric parameter $\delta \Delta$ and the oxygen coverage $\theta_{\mathrm{O}}$ can be represented by the equation:

$\theta_{\mathrm{O}}=0.7 \delta \Delta$.

The kinctics of the oxygen adsorption confirm the dissociative adsorption via a mobile precursor state, as reported in ref. [1].

\section{Results}

The oxygen covered $\mathrm{Cu}(111)$ surface was exposed to hydrogen in the pressure range of $2 \times 10^{-5}$ to $5 \times 10^{-4}$ Torr, at crystal temperatures between 240 and $430^{\circ} \mathrm{C}$, and at oxygen coverages between 0.2 and 0.5 monolayer. The reaction rate, starting with half a monolayer of oxygen was immeasurably small below crystal temperatures of $240^{\circ} \mathrm{C}$ and hydrogen pressures as high as $5 \times 10^{-4}$ Torr. At higher crystal temperatures the reaction rate is independent of the temperature at which the clean $\mathrm{Cu}(111)$ surface was covered with oxygen. The preadsorbed oxygen was quantitatively removed from the copper surface after reaction with hydrogen.

Fig. 1 shows the change in the ellipsometric parameter $\delta \Delta$ starting with half a monolayer of oxygen on the $\mathrm{Cu}(111)$ surface at crystal temperatures ranging
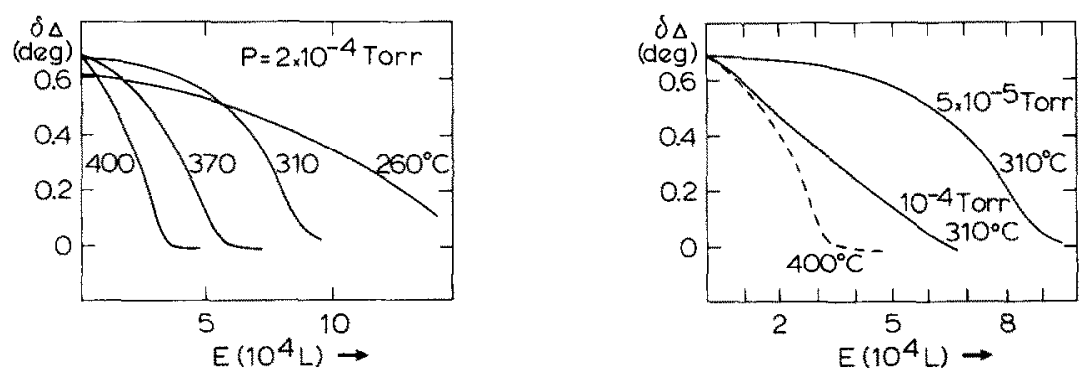

Fig. 1. Change in $\delta \Delta\left(=1.4 \theta_{\mathrm{O}}\right)$ upon removal of half a monolayer of oxygen from $\mathrm{Cu}(111)$ by hydrogen at $2 \times 10^{-4}$ Torr. Crystal temperatures (in ${ }^{\circ} \mathrm{C}$ ) are indicated in the figure. At $430^{\circ} \mathrm{C}$ the reaction curve is virtually identical to that of $400^{\circ} \mathrm{C}$.

Fig. 2. Removal of half a monolayer of oxygen from $\mathrm{Cu}(111)$ by $\mathrm{H}_{2}$. At lower crystal temperatures the reaction does not scale as $p \times t$ (solid lines). At higher temperatures the extent of the reaction is strictly proportional to the exposure. 
from $260-430^{\circ} \mathrm{C}$ and at a hydrogen pressure of $2 \times 10^{-4}$ Torr. When the reaction was started at a lower oxygen coverage, the corresponding part of the curve was reproduced. Between 370 and $430^{\circ} \mathrm{C}$ the extent of the reaction was proportional to $p \times t$. At temperatures below $370^{\circ} \mathrm{C}$ the $\delta \Delta$ versus exposure curves were no longer identical for different pressures of hydrogen. In fig. 2 the reaction curves are depicted at two crystal temperatures, $310^{\circ} \mathrm{C}$ and $430^{\circ} \mathrm{C}$, for hydrogen pressures of $1 \times 10^{-4}$ and $5 \times 10^{-5}$ Torr.

The reaction rates were calculated as $\mathrm{d}(\delta \Delta) / \mathrm{d}(p t)$ from the linear parts of the reaction curves. It can be concluded that the reaction rate is first order with respect to the hydrogen pressure above $370^{\circ} \mathrm{C}$.

The Arrhenius plot of the reaction probability, defined as the number of oxygen atoms removed per incident $\mathrm{H}_{2}$ molecule, is given in fig. 3. It shows that the apparent activation energy, $E_{\text {act }}$, increases with increasing temperature. Phenomenologically two regions could be distinguished from the Arrhenius plot: $340<T<430^{\circ} \mathrm{C}$ with $E_{\text {act }}=65 \pm 5 \mathrm{~kJ} / \mathrm{mol}$ and $260<T<340^{\circ} \mathrm{C}$ with $E_{\text {act }}=5 \pm 2 \mathrm{~kJ} / \mathrm{mol}$.

During the experiments we found that the ion gauge affected the reaction rate. All the results given above have been obtained with the ion gauge respectively switched on and off. The reaction curves with the ion gauge on were always straight lines in the whole temperature range of $260-430^{\circ} \mathrm{C}$ and the reaction rates were first order in the hydrogen pressure. Fig. 4 shows the effect of the ion gauge on the reaction at $400^{\circ} \mathrm{C}$ and hydrogen pressure $2 \times 10^{-4}$ Torr. It is seen that the reaction probability is increased markedly, although its temperature dependence is rather small (see fig. 3 , dotted line).
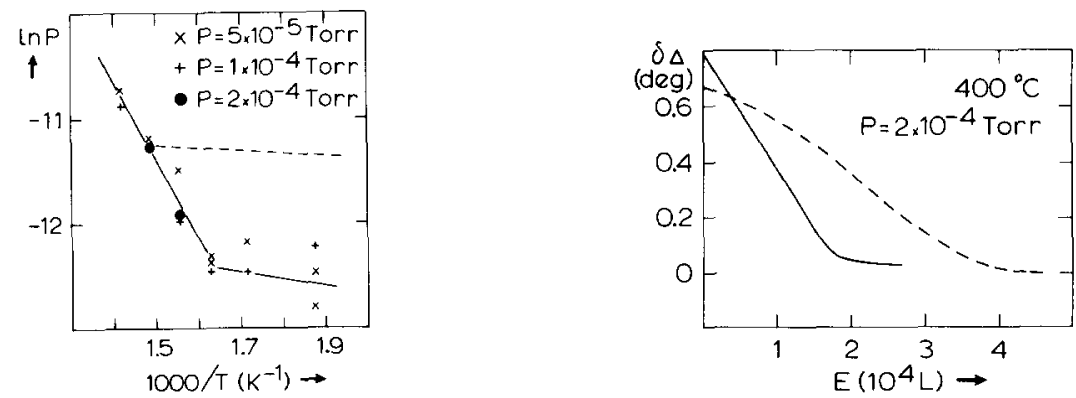

Fig. 3. Arrhenius plot of the reaction probability $(P)$ as a function of $1 / T ; P$ is defined as the number of oxygen atoms removed per incident hydrogen molecule. Dashed line: with ionization gauge operating. Solid line: ionization gauge switched off during reaction. Note that at low temperatures the reaction is pressure dependent if the ion gauge is switched off.

Fig. 4. Effect of an operating ion gauge on the reaction curve at $400^{\circ} \mathrm{C}, p\left(\mathrm{H}_{2}\right)=2 \times 10^{-4}$ Torr: $(-)$ gauge on; $(--$,$) gauge off.$ 


\section{Discussion}

It is obvious from fig. 4 that the effect of an operating pressure gauge is significant in accelerating the reaction. Since the reduction involves atomic hydrogen, the effect of the ion gauge must be to facilitate the dissociation of $\mathrm{H}_{2}$. Similar effects have been reported for the adsorption of $\mathrm{O}_{2}$ on $\mathrm{Ag}$ [13], the reduction of $\mathrm{O} / \mathrm{Ni}(100)$ by $\mathrm{H}_{2}$ [14], the decomposition of $\mathrm{CO}$ on $\mathrm{Ni}(100)$ [15] and the oxidation of $\mathrm{C}$ on $\mathrm{Ni}(100)$ by $\mathrm{O}_{2}$ [16]. In all cases the breaking of an interatomic bond is easier for diatomics that have "seen" an operating ion gauge. This is not entirely a consequence of a decrease in the bond strength upon ion formation as can be seen from table 1 . In contrast to $\mathrm{CO}$ and $\mathrm{H}_{2}$, the $\mathrm{O}_{2}^{+}$dissociation energy is actually larger than that for $\mathrm{O}_{2}$. It might, however, be linked to an increased stability of the molecular-ion precursor state due to its image force, analogous to the promotor function of $\mathbf{K}$ for the dissociation of $\mathrm{N}_{2}$ on iron [18]. The higher rate of adsorption of atoms, particularly $\mathrm{H}$ atoms has of course been known for a long time [19,20], but since in our experimental set-up the pressure gauge is not in line of sight with the copper crystal, we believe that some excited or ionized molecular hydrogen species is involved in the reaction. In any case the general reaction scheme may be written as:

$$
\begin{aligned}
& \mathrm{H}_{2(\mathrm{~g})} \underset{k_{1}}{\stackrel{k_{2}}{\leftrightarrows}} \mathrm{H}_{2(\mathrm{ad})} \underset{k_{3}}{\stackrel{k_{4}}{\leftrightarrows}} 2 \mathrm{H}_{(\mathrm{ad})}, \\
& \mathrm{H}_{(\mathrm{ad})}+\mathrm{O}_{(\mathrm{ad})} \underset{k_{5}}{\stackrel{\mathrm{k}_{6}}{\leftrightarrows}} \mathrm{OH}_{(\mathrm{ad})}, \\
& \mathrm{H}_{(\mathrm{ad})}+\mathrm{OH}_{(\mathrm{ad})} \underset{k_{7}}{\stackrel{k_{8}}{\leftrightarrows}} \mathrm{H}_{2} \mathrm{O}_{(\mathrm{ad})}, \\
& \mathrm{H}_{2} \mathrm{O}_{(\mathrm{ad})} \underset{k_{9}}{\rightarrow} \mathrm{H}_{2} \mathrm{O}_{(\mathrm{g})} .
\end{aligned}
$$

When the ionization gauge is operating the experimental results give a reaction curve which is first order with respect to the hydrogen pressure and zero order in the oxygen coverage (cf. fig. 4, solid line). This implies that adsorbed hydrogen atoms cannot be in equilibrium with adsorbed hydrogen molecules, since then a square root dependence on $p\left(\mathrm{H}_{2}\right)$ would result. Also, a

Table 1

Dissociation energies $D$ (in $\mathrm{eV}$ ) of diatomics and their positive ion; from ref. [17]

\begin{tabular}{llllll}
\hline $\mathrm{CO}$ & $\mathrm{CO}^{+}$ & $\mathrm{O}_{2}$ & $\mathrm{O}_{2}^{+}$ & $\mathrm{H}_{2}$ & $\mathrm{H}_{2}^{+}$ \\
\hline 11.1 & 9.9 & 5.1 & 6.5 & 4.5 & 2.6 \\
\hline
\end{tabular}


zero order oxygen coverage dependence suggests a rate-limiting step before any reaction with adsorbed oxygen. A logical consequence is then to take $k_{3}\left[\mathrm{H}_{2(\mathrm{ad})}\right]$ $\gg k_{4}\left[\mathrm{H}_{(\mathrm{ad})}\right]^{2}$ from which it follows that:

$\mathrm{d}\left[\mathrm{O}_{(\mathrm{ad})}\right] / \mathrm{d} t=-\frac{2 k_{1} k_{3}}{k_{2}+k_{3}} p\left(\mathrm{H}_{2}\right)$.

Eq. (6) describes the experiments with the pressure gauge on quantitatively. The reaction is zero order in $\mathrm{O}_{\text {(ad) }}$ and first order in hydrogen pressure. Its activation energy, $5 \mathrm{~kJ} / \mathrm{mol}$, is less than the activation energy of dissociative hydrogen chemisorption on copper, $12 \mathrm{~kJ} / \mathrm{mol}$ [9] due to the pressure gauge effect. In fact, the present analysis is entirely analogous to that given for the reaction of oxygen with hydrogen on a $\mathrm{Cu}-\mathrm{Ni}(110)$ alloy [21], the only difference being that in the latter case $\mathrm{Ni}$ sites, rather than the operating ion gauge, facilitate hydrogen dissociation.

The experiments with the ion gauge switched off are more difficult to interpret. The shape of the reaction curves (figs. 1 and 2) is clearly not described by eq. (6). Also a more general solution of eqs. (2)-(5), as given earlier [21], without the assumption that $k_{3}\left[\mathrm{H}_{2(\text { ad })}\right] \gg k_{4}\left[\mathrm{H}_{(\text {ad })}\right]^{2}$, always yields reaction curves that are either straight lines or exponential-like, but an increase in the reaction rate can never be reproduced. We are thus forced to make additional assumptions about the detailed mechanism. A clue as to where these additions may have to be made can in fact be obtained from the experimental data. The initial slow rate at high oxygen coverage suggests that the presence of oxygen does not enhance the dissociation of hydrogen, since in that case one would expect an initially large reaction rate, which decreases with decreasing oxygen coverage. Rather the reverse seems to be the case, oxygen blocking sites for hydrogen dissociation. Since in the temperature range $370-430^{\circ} \mathrm{C}$ the extent of the reaction is proportional to the exposure $\left(p\left(\mathrm{H}_{2}\right) \times t\right)$ no equilibrium between adsorbed hydrogen atoms and molecules exists. Qualitatively our results (figs. 1 and 2) are the same as those of Hachicha et al. [12] for $\mathrm{Cu}(110)$, who also report a proportionality with hydrogen exposure and a similar shape of the reaction curve. Thus the formation of $\mathrm{OH}$ groups on $\mathrm{Cu} / \mathrm{O}$ must be much faster than the recombination of hydrogen atoms on the surface. The results of Pritchard [22], who found reversible adsorption of $\mathrm{H}_{2}$ on $\mathrm{Cu}$ around room temperature, are not at variance with this conclusion. 'The hydrogen atom concentration in our case of high temperature will be extremely small and encounters between two $\mathrm{H}$ atoms will be much more infrequent than between an adsorbed $\mathrm{H}$ and $\mathrm{O}$ atom.

The simplest way of taking all this into account is to put:

$k_{3}=k_{3}^{\prime}\left(1-\theta_{0}\right), \quad k_{4}=0$,

which implies that hydrogen dissociation only occurs on pure copper sites. Using the stationary state condition for adsorbed hydrogen molecules a 
numerical solution of eqs. (2), (3) and (7) is possible. In the temperature range $370-430^{\circ} \mathrm{C}$, where the apparent activation energy is about $65 \mathrm{~kJ} / \mathrm{mol}$, good fits to the observed reaction curves could be obtained by this procedure. This is

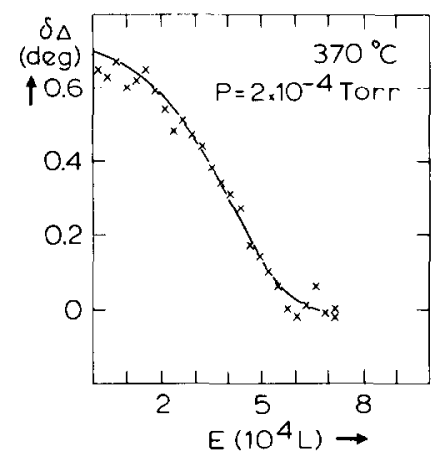

Fig. 5. Comparison of observed $(x)$ and calculated (_-) reaction curve for oxygen removal from $\mathrm{Cu}(111) ; p\left(\mathrm{H}_{2}\right)=2 \times 10^{-4} \mathrm{Torr}, T=370^{\circ} \mathrm{C}$.

illustrated in fig. 5. As usual in kinetic studies, this success only makes our mechanism, viz. dissociation of hydrogen on pure copper sites and no hydrogen dissociation equilibrium, a probable and not impossible one. It does, however, account satisfactorily for the observed data.

From the calculations the activation energy of $k_{5}$, the formation of $\mathrm{OH}$ groups from $\mathrm{O}_{(\mathrm{ad})}$ and $\mathrm{H}_{(\mathrm{ad})}$, could be extracted. Its value is $93 \pm 12 \mathrm{~kJ} / \mathrm{mol}$. This is about equal to the value reported by Hachicha et al. [12], viz. $82 \pm 6$ $\mathrm{kJ} / \mathrm{mol}$, for the same reaction on $\mathrm{Cu}(110)$. On $\mathrm{Cu}-\mathrm{Ni}(110)$ the activation energy for this process has also been given as $80 \mathrm{~kJ} / \mathrm{mol}$, if the reaction takes

\section{Table 2}

Reaction probabilities for the oxidation of $\mathrm{CO}$ and $\mathrm{H}_{2}$ on copper surfaces and their activation energies; data taken from refs. [1-4,12] and the present work

\begin{tabular}{|c|c|c|c|c|}
\hline & $p(\mathrm{CO})$ & $\begin{array}{l}E_{\text {act }}(\mathrm{CO}) \\
(\mathrm{kJ} / \mathrm{mol})\end{array}$ & $p\left(\mathrm{I}_{2}\right)$ & $\begin{array}{l}E_{\mathrm{act}}\left(\mathrm{H}_{2}\right) \\
(\mathrm{kJ} / \mathrm{mol})\end{array}$ \\
\hline \multicolumn{5}{|l|}{$\mathrm{Cu}(111)$} \\
\hline $350^{\circ} \mathrm{C}$ & $1.4 \times 10^{-4}$ & \multirow{2}{*}{33} & $5.2 \times 10^{-6}$ & \multirow{2}{*}{65} \\
\hline $440^{\circ} \mathrm{C}$ & $3.1 \times 10^{-4}$ & & $2.4 \times 10^{-5}$ & \\
\hline \multicolumn{5}{|l|}{$\mathrm{Cu}(110)$} \\
\hline $350^{\circ} \mathrm{C}$ & $7.9 \times 10^{-9}$ & \multirow{2}{*}{26} & $3 \times 10^{-7}$ & \multirow{2}{*}{82} \\
\hline $440^{\circ} \mathrm{C}$ & $9.8 \times 10^{-5}$ & & $2 \times 10^{-6}$ & \\
\hline \multicolumn{5}{|l|}{$\mathrm{Cu}(100)$} \\
\hline $350^{\circ} \mathrm{C}$ & $2.2 \times 10^{5}$ & \multirow{2}{*}{29} & $4.5 \times 10^{-5}$ & \multirow{2}{*}{-} \\
\hline $440^{\circ} \mathrm{C}$ & $4.5 \times 10^{-5}$ & & - & \\
\hline
\end{tabular}


place on copper sites [21]. We can thus conclude that the hydrogen-oxygen reaction on $\mathrm{Cu}$ surfaces is determined by the initial formation of adsorbed $\mathrm{OH}$ groups (with activation energies in the range $80-92 \mathrm{~kJ} / \mathrm{mol}$ ) and that the reaction is not particularly plane-specific. Similar conclusions have been drawn with respect to the $\mathrm{CO}$ oxidation on the low index copper faces [4]. The activation energy for the Langmuir-Hinshelwood reaction of adsorbed $\mathrm{CO}$ and $\mathrm{O}$ is $75-84 \mathrm{~kJ} / \mathrm{mol}$, independent of the crystallographic orientation. The reaction probabilities, however, are different for $\mathrm{H}_{2}$ and CO. Table 2 summarizes these probabilities at 350 and $440^{\circ} \mathrm{C}$ and their corresponding activation energies. It is seen that, at least for the two surfaces where data are available, carbon monoxide is oxidized much more readily than hydrogen. Also the more densely packed (111) face is more easily reduced than the less dense surfaces by both reactants.

\section{Acknowledgements}

The authors thank Mr. A.J.M. Mens for technical assistance. The investigations were supported by the Netherlands Foundation of Chemical Research (SON) with financial aid from the Netherlands Organization for the Advancement of Pure Research (ZWO).

\section{References}

[1] F.H.P.M. Habraken, E.Ph. Kieffer and G.A. Bootsma, Surface Sci. 83 (1979) 45.

[2] F.H.P.M. Habraken and G.A. Bootsma, Surface Sci. 87 (1979) 333.

[3] F.H.P.M. Habraken, G.A. Bootsma, P. Hofmann, S. Hachicha and A.M. Bradshaw, Surface Sci. 88 (1979) 285.

[4] F.H.P.M. Habraken, C.M.A.M. Mesters and G.A. Bootsma, Surface Sci. 97 (1980) 264.

[5] J.F. Wendelken, Surface Sci. 108 (1981) 605.

[6] A.F. Armitage and D.P. Woodruff, Surface Sci. 114 (1982) 414.

[7] L.J. Hanekamp, W. Lisowski and G.A. Bootsma, Surface Sci. 118 (1982) 1.

[8] A. Spitzer and H. Lüth, Surface Sci. 118 (1982) 121, 136.

[9] M. Balooch, M.J. Cardillo, D.R. Miller and R.E. Stickney, Surface Sci. 46 (1974) 358.

[10] M.J. Cardillo, M. Balooch and R.E. Stickney, Surface Sci. 50 (1975) 263.

[11] A. Gelb and M.J. Cardillo, Surface Sci. 59 (1976) 128; 64 (1977) 197.

[12] S. Hachicha, P. Hofmann and A.M. Bradshaw, in: Proc. IVC-8, ICSS-4 and ECOSS-3. Cannes, 1980, p. 498.

[13] H. Albers, W.J.J. van der Wal and G.A. Bootsma, Surface Sci. 68 (1977) 47.

[14] P.K. de Bokx, F. Labohm, O.L.J. Gijzeman, G.A. Bootsma and J.W. Geus, Appl. Surface Sci. 5 (1980) 321.

[15] F. Labohm, C.W.R. Engelen, O.L.J. Gijzeman, J.W. Geus and G.A. Bootsma, J. Chem. Soc. Faraday Trans. I, 78 (1982) 2435.

[16] F. Labohm, C.W.R. Engelen, O.L.J. Gijzeman, J.W. Geus and G.A. Bootsma, Surface Sci. 126 (1983) 429. 
[17] G. Hertzberg, Molecular Spectra and Molecular Structure, Vol. 1, Spectra of Diatomic Molecules (Van Nostrand-Reinhold, Princeton, NJ, 1950).

[18] G. Ertl, M. Weiss and S.B. Lee, Chem. Phys. Letters 60 (1979) 391.

[19] G. Ehrlich, J. Chem. Phys. 31 (1959) 1111.

[20] V. Ponec, Z. Knor and S. Cerny, J. Catalysis 4 (1965) 485.

[21] C.M.A.M. Mesters, A.F.H. Wielers, O.L.J. Gijzeman, G.A. Bootsma and J.W. Geus, Surface Sci. 117 (1982) 605

[22] J. Pritchard, Nature 205 (1965) 1208. 